ISSN 1518-3483

Licenciado sob uma Licença Creative Commons

(c) (1)

\title{
A cultura escolar em conflito: ensino técnico e matemática moderna em Portugal
}

\author{
School culture in conflict: professional schools and modern \\ mathematics in Portugal
}

\section{Culture scolaire en conflit: enseignement professionnelle $e$ mathématiques modernes au Portugal}

\author{
Alexandra Rodrigues ${ }^{[a]}$, Barbara Winiarski Diese Novaes ${ }^{[b]}$, José Manuel Matos ${ }^{[c]}$ \\ [a] Instituto de Gouveia - Escola Profissional, Gouveia, Portugal \\ [b] Universidade Tecnológica Federal do Paraná (UTFPR), Toledo, PR, Brasil \\ [c] Universidade Nova de Lisboa (UNL), Lisboa, Portugal
}

\section{Resumo}

O artigo estuda as transformações exigidas às escolas do ensino profissional português durante a reforma da matemática moderna que ocorrem a partir de finais dos anos 1960. Em primeiro lugar, traça um quadro das normas associadas às escolas técnicas portuguesas antes da reforma, recorrendo à legislação fundadora, aos manuais e a artigos de opinião de professores. Em segundo, detalha o debate que antecipou a introdução da reforma recorrendo a artigos e a

\footnotetext{
* AM: Doutora, e-mail: alexsofiarod@gmail.com

BWDM: Doutora, e-mail: barbaradiesel@yahoo.com.br

JMM: Doutor, e-mail: jmm@fct.unl.pt
} 
opiniões expressas durante os cursos preparatórios, onde são notórias as pressões para mudanças na cultura escolar, especialmente nas suas representações, suscitadas pela nova matemática. Finalmente, observar-se como se materializou a reforma nos livros de texto da experiência.

Palavras-chave: Cultura escolar. Desenvolvimento curricular. Matemática Moderna. Ensino Técnico Profissional.

\section{Abstract}

The article studies the transformations required in the late 1960s by Portuguese professional schools during the reform of modern mathematics. Firstly, the text describes the norms associated with Portuguese technical schools before the reform, drawing on founding legislation, manuals and teachers' articles. Secondly, the article details the debate that anticipated the introduction of the reform by using articles and opinions expressed during the preparatory courses, where pressures for change in the school culture from the new mathematics are visible. Finally, the experimental textbooks are studied.

Keywords: School culture. Curriculum development. Modern mathematics. Technical and Vocational Education.

\section{Resumé}

L'article étudie les transformations exigées aux écoles de formation professionnelle lors de la réforme des mathématiques modernes portugaises qui se sont produises depuis les années 1960. Premièrement, on esquisse un tableau des normes associées aux écoles techniques portugaises avant la réforme, en utilisant les normes législatives, les manuels et articles d'opinion des enseignants. Après, le débat qui précède l'introduction de la réforme est détaillé, en utilisant articles et opinions écrits pendant les cours préparatoires, où les pressions pour des changements dans la culture de l'école poussés par la nouvelle mathématique sont évidents, surtout dans les représentations des finalités de l'école technique. Finalement, on voit comme la réforme est matérialisé dans les manuels écrits pour l'expérience.

Mosts-clés: Culture scolaire. Développement du curriculum. Mathématiques modernes. École techniques. 


\section{Introdução}

Com este texto pretendemos detalhar as transformações exigidas às escolas do ensino profissional português durante a reforma da matemática moderna que ocorrem a partir de finais dos anos 1960. Recorreremos ao conceito de cultura escolar de Julia (2001, p. 10, itálicos no original) como um "conjunto de normas que definem conhecimentos a ensinar e condutas a inculcar, e um conjunto de práticas que permitem a transmissão desses conhecimentos e a incorporação desses comportamentos".

Dividiremos o trabalho em três partes. Em primeiro lugar, traçaremos um quadro das normas associadas às escolas técnicas portuguesas antes da reforma, recorrendo à legislação fundadora, aos manuais e a artigos de opinião de professores. Em segundo, detalharemos o debate que antecipou a introdução da reforma, recorrendo a artigos e a opiniões expressas durante os cursos preparatórios onde as pressões para a mudança na cultura escolar, especialmente nas suas representações, que a nova matemática suscita. Finalmente, observaremos como se materializou a reforma nos livros de texto da experiência. Esta investigação fez parte de um projeto mais amplo que visou estudar comparativamente a introdução da Matemática Moderna nas escolas do Brasil e em Portugal.

\section{A matemática no Ensino Técnico de Pires de Lima}

Com o Estatuto do Ensino Técnico Profissional (PORTUGAL, Decreto ${ }^{\circ}$ 37.029/1948) o Ministro Pires de Lima pretendia dotar Portugal de um sistema de formação profissional após os quatro anos do ensino primário que acompanhasse as tendências de desenvolvimentos do pós-guerra. Com as suas escolas próprias, esta reforma do ensino técnico previa diferentes tipos de cursos. Por um lado, um Ciclo Preparatório genérico de dois anos após o ensino primário e que dava acesso a Cursos de Formação específicos e depois a cursos de acesso ao ensino profissional médio. Por outro, cursos elementares frequentados em simultâneo com uma prática profissional ou cursos mais 
especializados de formação de capatazes ou chefes de oficinas. Em paralelo com o ensino técnico existia o ensino liceal para o acesso às Universidades.

A estrutura curricular destes cursos era muito diferenciada e a matemática apresentava-se em programas diversos, com horas lectivas semanais variáveis. À imagem do que acontece hoje, os professores estavam agregados a grupos de disciplinas. O $1^{\circ}$ grupo compreendia a Matemática, a Física e Química, e os seus professores efetivos com certificação pedagógica poderiam ser licenciados em ciências matemáticas, físico-químicas, geofísicas ou engenheiros geógrafos. As disciplinas de matemática também podiam ser leccionadas por professores do $2^{\circ}$ grupo (Mecânica, Eletricidade, etc.), do $3^{\circ}$ (Desenhos e disciplinas tecnológicas), $4^{\circ}$ (Ciências Físico-Naturais, etc.) e do $11^{\circ}$ (um grupo diversificado que incluía professores com formação para o ensino primário). Nesta época, no entanto, os professores com certificação pedagógica eram uma minoria. Salvado Sampaio (1975) mostra como, em 1973/74, dos 9.393 professores do ensino comercial e industrial, apenas 1.618 $(17,2 \%)$ tinham habilitação completa.

Os programas para as disciplinas de matemática - Matemática e Cálculo Comercial (PORTUGAL, Portaria no 13.800/1952) enfatizam, muitas vezes, a importância de abordagens pedagógicas que mostrem a aplicação dos conceitos matemáticos à vida real e tomem em conta a futura profissão do aluno. A Matemática para o Ciclo Preparatório, destinada a alunos recém-chegados do ensino primário,

será mais formativa que informativa e a obtenção de resultados na solução de problemas ou nos exercícios de medição e cálculo estará sempre ligada com a crítica da viabilidade e utilidade desses mesmos resultados. [...]

As frequentes revisões de matéria, mais do que nunca necessárias, far-se-ão introduzindo factos novos como centros de interesses, e a revisão final de cada ano será o aproveitamento global dos conhecimentos adquiridos para aplicação em casos concretos da vida real (PORTUGAL, Portaria n ${ }^{0} 13.800 / 1952$, p. 28). ${ }^{1}$

1 As citações foram alteradas para a grafia atual. 
As recomendações para a Matemática dos Cursos de Formação seguintes continuam salientando a importância da aplicabilidade dos conceitos e a rejeitar os exercícios de memória associados às longas expressões algébricas ou "às regras, teoremas e definições" (PORTUGAL, Portaria no $13.800 / 1952$, p. 76):

Estuda-se matemática porque se precisa dela; mas somente se precisa daquilo que correntemente se utiliza, e não do que se confia à memória, para aí ficar muito arrumado em sequências lógicas, mas como bagagem só servirá no final da viagem, se até lá assim se conservar. Há que a manusear como necessidade quotidiana, ajustada ao interesse dos alunos; se fica em depósito sedimentar, nunca entrará no conhecimento atual dos que procuram, naquele - que está sempre presente e vivo - "saber de experiência feito". (PORTUGAL, Portaria $\mathrm{n}^{\mathrm{o}} 13.800 / 1952$, p. 76-77)

Distinta é a perspectiva adotada para o ensino liceal, reservado a alunos destinados aos estudos superiores, cujos programas de Matemática não contêm qualquer requisito de aplicabilidade à vida real. A ênfase é antes colocada nos aspetos formativos mais gerais e no desenvolvimento de hábitos de precisão de ideias e de linguagem, procurando dar uma visão da complexidade crescente dos temas matemáticos. Por exemplo, a álgebra não é vista do ponto de vista da sua aplicabilidade, mas antes como um prolongamento da aritmética, preparando o estudo futuro das funções e da análise (MATOS, 2014). A comparação entre a abordagem de frações em manuais destinados às escolas técnicas e aos liceus (SOUSA, 2012) revela uma profusão de representações e ligações ao concreto nas primeiras em contraste com a forma sintética e mais abstrata do livro único para os liceus.

Pelo contrário, nas escolas técnicas, mesmo em conceitos mais avançados, a preocupação com a ligação ao real está presente. Vejamos, por exemplo alguns exercícios propostos no tema monómios e polinómios pelo livro único de 1958 destinado ao $2^{\circ}$ ano dos Cursos de Formação industriais (correspondente ao $8^{\circ}$ ano de escolaridade atual) (Figura 1). 
1 - Qual a expressão algébrica que nos dá a área da superfície dum cubo expressa na diagonal d do cubo?

(Sabe-se que: Área do cubo $=6 \mathrm{a}^{2}$ e que: $\mathrm{d}^{2}=3 \mathrm{a}^{2}$, sendo $a$ a aresta do cubo).

Aplicação para $d=7$.

2 - A diferença de potencial entre as extremidades do filamento duma lâmpada eléctrica é E. O filamento é percorrido por uma corrente de intensidade I; que quantidade $\mathrm{Q}$ de calor se produz durante t segundos?

(Sabe-se que: $\mathrm{Q}=0,24 \mathrm{I}^{2} \mathrm{R}$ t e que $\mathrm{R}=\underline{\mathrm{E}}$ ).

Aplicação para:

$$
\begin{aligned}
& E=220 \text { volts } \\
& I=1 \text { ampére } \\
& t=80 \text { segundos }
\end{aligned}
$$

Figura 1 - Exercícios em monómios e polinómios Fonte: SILVA; ALMEIDA, sem data, p. 38.

Quase todos os capítulos dese livro único incluem aplicações e interligam diversos temas do programa e das outras disciplinas (Figura 2).

d) Que velocidade atinge um móvel, com a aceleração de $2 \mathrm{~m} / \mathrm{s}^{2}$, ao ter percorrido 100 metros?

(A fórmula que relaciona a velocidade com o espaço e a aceleração é $\mathrm{v}^{2}=2$ a e).

Figura 2 - Exercícios no tema Equação do 2ㅇ grau Fonte: SILVA; ALMEIDA, sem data, p. 62. 
Dois professores destacaram-se na reflexão pedagógica sobre o ensino técnico (SOUSA, 2012). O primeiro, Eduardo Rodrigues da Silva, engenheiro, professor e diretor da Escola Industrial Fonseca Benevides em Lisboa, autor de livros de texto e que acompanha no Ministério da Educação Nacional as reformas do final dos anos sessenta, publica artigos centrados nos primeiros dois anos do ensino técnico $(1952,1953,1960)$. O segundo, António Oleiro dos Santos Heitor, engenheiro, professor-metodólogo (isto é, responsável pela formação de novos professores) da Escola Marquês de Pombal também em Lisboa e autor de livros de texto, produz um conjunto de quatro artigos sobre o tema (1954a, 1954b, 1955a, 1955b). Ambos vão desenvolver um conjunto de sugestões pedagógicas específicas para o ensino técnico fundadas quer nas abordagens da Escola Nova quer em bases psicológicas. Por exemplo, no primeiro dos seus artigos, Santos Heitor carateriza deste modo os alunos do ensino técnico:

É sabido que a população das escolas técnicas profissionais é recrutada em camadas sociais de rudimentar cultura (pequenos funcionários, operários, empregados comerciais, etc.), em que o vocabulário usual é necessariamente mais restrito, principalmente no domínio da terminologia abstracta. [...]

Vindo deste meio, o aluno ingressa na escola com recursos restritos de percepção e expressão verbal; isto nos levará a considerá-lo, geralmente, como um tipo ideo-motor, ou seja, possuindo uma modalidade de inteligência particularmente sensível aos estímulos motrizes ou de base sensorial, dirigida para as coisas, dominada por princípios de utilidade realista, com predomínio de relações de finalidade, trabalhando com ideias esquemáticas (HEITOR, 1954a, p. 172).

Desta apreciação social e psicológica, Santos Heitor conclui da necessidade de empregar métodos ativos e a valorização da a intuição que vai desenvolver detalhadamente as suas propostas nos artigos restantes. Rodrigues da Silva, mais preocupado com os primeiros anos, vai propor abordagens centradas no trabalho de grupo, nos centros de interesse, com ligação ao concreto e ao real. 


\section{Antevendo a matemática moderna no Ensino Técnico}

A reforma da Matemática Moderna ocorre por todo o mundo, essencialmente durante os anos 60 e 70 do século passado. Embora com muitas variantes regionais, propõe uma profunda alteração nos conteúdos matemáticos adaptando-os aos paradigmas bourbakistas, retomando os métodos ativos propostos pelo movimento da Escola Nova desde os anos 1930 (MATOS, 2014). Os detalhes da introdução da Matemática Moderna nas escolas técnicas portuguesas é contada por um dos seus intervenientes diretos, o inspetor Leopoldino de Almeida, em intervenção pública de 1970. Recorda que, embora nos liceus essa introdução se tenha iniciado em 1963, foi então entendido que "tal estudo respeitava apenas ao ensino liceal" (ALMEIDA, 1970, p. 10) e os responsáveis do ensino técnico não desenvolveram qualquer ação.

Entretanto, no final dos anos sessenta começam a concretizar-se alterações fundamentais ao sistema educativo, entre elas a introdução do Ciclo Preparatório do Ensino Secundário (CPES) destinado a alunos entre 10 e 11 anos de idade. Este Ciclo, com as suas escolas próprias e o seu corpo docente específico, vem substituir o Ciclo Preparatório Elementar do Ensino Técnico e o $1^{\circ}$ Ciclo do Ensino Liceal a partir de 1968/69. Segundo o inspetor, ao se constatar que o programa de Matemática do CPES estava baseado nas novas abordagens, passou a ser necessário alterar os programas do ensino técnico (ALMEIDA, 1970). Assim, são organizados diversos cursos para formação de professores, o primeiro no final de 1966 e, em 1967 são criadas turmas experimentais para Cursos de Formação Industrial. Estas atividades são acompanhadas pela publicação mensal da Folha Informativa dos Professores do $1^{\circ}$ Grupo (E.T.P.) que é o primeiro periódico português consagrado exclusivamente à educação matemática (RODRIGUES, 2014).

A Folha destinava-se aos professores de todo o país responsáveis pela leccionação das disciplinas relacionadas com a matemática, e publica 66 números e 9 suplementos até fevereiro de 1972. O seu diretor é Aires António Silva Biscaia, licenciado em matemática e na época diretor da 
Escola Industrial e Comercial de Sintra, onde a revista é produzida. Durante os seus quase seis anos de existência, a Folha Informativa vai publicar não só muitos artigos relacionados com a reforma da Matemática Moderna (textos matemáticos, programas em experimentação, relatos de experiências de aula, testes, etc.), mas também outro tipo de artigos, nomeadamente relacionando a matemática com a física, bibliografias recomendadas, pequenos artigos de matemática ou de física recreativa, problemas de almanaque, etc. (MATOS, NOVAES e GABRIEL, 2009; NOVAES, 2012).

A primeira citação que explicita o sentido da reforma pretendida aparece no artigo de abertura de março de 1967 "Matemática moderna, porquê?", da seguinte maneira:

Todos os que se interessam pelo ensino têm sentido, ultimamente, uma acentuada tendência para uma restruturação dos programas de Matemática em virtude de se considerar como imperiosa a necessidade duma modernização da linguagem nos assuntos fundamentais (REDAÇÃO, 1967, p. 1).

Um pouco mais à frente explicita que se pretende "modernizar a linguagem dos assuntos considerados imprescindíveis na formação do estudante usando os conceitos de conjunto e de estruturas" (REDAÇÃO, 1967, p. 1).

Ressalta depois que o uso das estruturas acaba com os compartimentos estanques em Matemática (aritmética, álgebra, geometria) e que é fundamental o uso de símbolos lógicos "que respondem pela precisão que deve exigir-se nesta ciência" (REDAÇÃO, 1967, p. 2) e "assim como hoje professores e alunos não podem passar sem o uso de certos símbolos, como $=,+, \mathrm{x}, \ldots$ também no futuro se tornarão indispensáveis os quantificadores universal e existencial e outros símbolos que permitem uma forma correta de expressão (REDAÇÃO, 1967, p. 2).

$\mathrm{O}$ artigo garante a nova matemática como fundada teoricamente nos trabalhos de Piaget que "mostrou, exaustivamente, a correspondência existente entre as estruturas algébricas e os mecanismos operatórios da inteligência de uma criança" (REDAÇÃO, 1967, p. 1), nos de Boole que "pôs em evidência a existência duma 'álgebra do pensamento' que sob 
a forma de estruturas se exprime pela língua e se revela pela gramática" (REDAÇÃO, 1967, p. 1), e no desenvolvimento tecnológico. Em julho de 1967 é decidido avançar para uma reforma dos programas, experimentando-os no ano lectivo seguinte (1967/68). O $2^{\circ}$ curso, que se realizará em outubro de 1967, seria então centrado na "exploração da atual conceitualização de Matemática Moderna” (HEITOR, 1967b, p. 1).

Em dois artigos de preparação do curso, Santos Heitor vai refletir sobre a viabilidade de uma abordagem de Matemática Moderna no contexto do ensino técnico português. As linhas de intervenção da reforma são claramente colocadas num primeiro artigo em julho de 1967:

I - A finalidade do ensino da Matemática nas nossas Escolas [Industriais], parece-nos ser a de contribuir para formar agentes de ação sobre o mundo exterior.

II - Esta contribuição seria dirigida, numa $1^{\text {a }}$ fase para a formação de operários; mas processar-se-ia com a abertura indispensável para o eventual prosseguimento, dentro de três principais direções:

a) A duma promoção a profissões mais exigentes de aptidões e conhecimentos matemáticos (mestres, agentes de métodos ou de planificação do trabalho, agentes técnicos, engenheiros, etc.)

b) A duma comparticipação cada vez mais acentuada numa sociedade tecnológica e económica, comparticipação esta que, inclusivamente, a nossa legislação do trabalho deixa supor.

c) A duma "mentalização matemática" capaz de permitir ao indivíduo a apreensão da complexidade de estruturas do mundo atual. Num cume de objectivos, até formar "matemáticos profissionais". (HEITOR, 1967a, p. 3)

Devemos ler com atenção as palavras de Santos Heitor, que era a principal referência da comissão recentemente nomeada para preparar a introdução da matemática moderna nas escolas técnicas. Em 1957 ele tinha sido o representante português do ensino técnico à reunião de Madrid da Commission Internationale pour l'Étude et l'Amélioration de l'Enseignement Mathématique, acompanhando Sebastião e Silva e Jorge Calado que vão ter um papel fundamental na reforma da matemática moderna nos liceus (MATOS, 
2014). Na sequência desta participação, publica um artigo (HEITOR, 1958) onde são pela primeira vez divulgados em Portugal os novos materiais para o ensino da matemática: as barras Cuisennaire, o geoplano, entre outros.

As propostas da Matemática Moderna têm algumas dificuldades de adaptação ao ensino profissional, como o próprio Santos Heitor indica. A cultura escolar das escolas técnicas (as suas normas e práticas no sentido de Julia) valorizava um ensino funcional, centrado em técnicas aplicáveis por alunos destinados ao mundo industrial e não visava as abordagens generalistas das grandes estruturas, nem incorporava a necessidade de uma linguagem da teoria de conjuntos desconhecida no mundo exterior à escola na qual as novas tendências assentavam. Para resolver esta contradição, Santos Heitor defende que a abordagem moderna deverá permitir uma progressão profissional por um lado, e, por outro, uma compreensão do mundo de um modo mais abrangente.

Em resumo: a finalidade mais restritamente utilitária da educação matemática dos futuros operários deverá ser interpenetrada duma autêntica fase, gradual e progressiva, de educação formativa de "matemáticos". Como "matemáticos" entendemos, aqui, indivíduos capazes de apreender relações matemáticas e, daí, relações lógicas mais gerais. (HEITOR, 1967a, p. 3)

Isto é, Santos Heitor entende que interligando as novas tendências com uma preocupação de aplicabilidade dos conceitos matemáticos, se estará, aumentando o âmbito da formação possibilitando uma melhor compreensão do mundo, por um lado, e facilitando adaptações profissionais posteriores.

Na sequência das suas propostas, Santos Heitor avança com algumas linhas gerais para a formação matemática nas Escolas Industriais e assente no desenvolvimento de modelos:

1) A criação de modelos matemáticos dos fenómenos do mundo físico (Física, Química, Tecnologia, etc.)

2) A interpretação desses modelos.

3) A sua transformação para o estudo de fenómenos análogos. 
4) O enriquecimento interpretativo destes novos modelos, permitindo o prosseguimento e diversificação da cadeia atrás esboçada. (HEITOR, 1967a, p. 4)

Santos Heitor retoma um tema antigo. A reunião de Madrid de 1957 tinha sido dedicada ao tema dos modelos e materiais no ensino da matemática e no seu relato ele tinha abordado longamente o assunto discutindo as suas aplicações ao ensino técnico português (HEITOR, 1958). A reforma, entende ele agora, deveria ser centrada na exploração de modelos pressupondo:

Que o espírito desta matemática se não queira impor, através de qualquer axiomatização demasiado avançada ou prematura para o desenvolvimento mental dos nossos alunos.

Que se condene a invocação de qualquer estrutura matemática "à la Bourbaki", sempre que ela se revele incapaz de abranger, com a necessária fidelidade, o modelo analógico a estudar.

Que se aproveitem, com sentido didático de adaptação, as grandes vantagens de esclarecimento, simplificação e unificação no desenvolvimento de um curriculum que, contudo, não seria determinado pela necessidade de ensinar matemática moderna "per se". (HEITOR, 1967a, p. 4-5, grifo no original).

Num segundo artigo de reflexão publicado em julho de 1967, Santos Heitor escreve que "o $\left[2^{\circ}\right]$ curso não será sobre Matemática Moderna, mas sim sobre a contribuição notável que esta traz a um processo de renovação e atualização do ensino" (HEITOR, 1967b, p. 1), querendo talvez significar que o curso não seria uma leccionação formal de teorias matemáticas, mas antes uma troca de opiniões sobre tópicos curriculares e métodos de ensino.

$\mathrm{Na}$ abertura do $2^{\circ}$ curso em outubro desse ano, Santos Heitor explicitará melhor a questão principal: 
Deverá o aluno tornar-se no profissional limitado às capacidades obreiras primárias diretamente utilizáveis na profissão, ou teremos de encarar, pelo contrário, o profissional a promover dentro da profissão ou mesmo a ascender a níveis mais elevados de formação? Ou de outra maneira: Carece o nosso aluno apenas da aquisição das técnicas de cálculo necessárias às tarefas profissionais básicas, ou, acima delas e fundamentalmente, como valor perdurável e transferável (sic), importa mais proporcionar-lhe uma formação intelectual que assegure ao 'profissional' a sua adaptação a um mundo em evolução, cuja trajetória é talvez imprevisível mas rápida (PEREIRA, 1967, p. 6)

A sua proposta de formar matemáticos no ensino técnico está agora mais aprofundada e ele imagina que a Matemática Moderna possa ser uma via para dotar os alunos das escolas técnicas com uma formação matemática mais abrangente e por isso mais adaptável a evoluções tecnológicas futuras.

Não encontramos nestes artigos a visão humanista da matemática para o ensino liceal que na mesma época é possível detetar em Sebastião e Silva (MATOS, 2014), mas devemos recordar-nos que em 1967 o país vivia em ditadura e qualquer referência menos crítica do que "a apreensão da complexidade de estruturas do mundo atual" ou "apreender [...] relações lógicas mais gerais" quando se falava da formação de operários, não seria tolerada. Sabemos que Santos Heitor deveria ter um espírito aberto para outras realidades, pois, após a revolução democrática ele se manteve como diretor da Escola Marquês de Pombal participando ativamente na construção de uma nova escola democrática (NOVAES, 2012).

Temos algumas informações sobre o modo como as novas ideias foram recebidas pelos presentes no $2^{\circ}$ curso a partir do relato publicado nas Folhas por Vítor Pereira, licenciado em matemática e professor na Escola Comercial e Industrial de Sintra:

A Assembleia esteve um pouco dividida, como é aliás natural, quanto à introdução de aspectos modernos das Matemáticas no nosso ensino de formação Industrial, admitindo como dificuldade mais saliente a 
necessidade de prática de cálculo que os alunos que nele se formam devem estar possuídos (PEREIRA, 1967, p. 9).

Sabemos também que um dos orientadores, Eugénio Monteiro (1923-2008), metodólogo na Escola Industrial e Comercial Brotero em Coimbra, se revela um adepto da Matemática Moderna, enquanto que Álvaro Pereira Gomes (1922-2007), licenciado em matemática, diretor e metodólogo da Escola de Artes Decorativas Soares dos Reis no Porto, não se mostra entusiasmado:

[Álvaro Pereira Gomes] não sendo refractário às Matemáticas Modernas entende que é necessário destacar as Matemáticas Práticas para acompanhar as outras disciplinas. "Tenho muito respeito pelo aspecto formativo mas também tenho muito respeito pela parte de aplicação que no Ensino Técnico deve pesar imenso" (PEREIRA, 1968, p. 13-14).

Temos também opiniões de professores que responderam ao questionário que precedeu o Curso. Tal é o caso de Adriano Vaz Velho, diretor da Escola Industrial e Comercial de Montemor-o-Novo e colaborador assíduo das Folhas, que enfatiza fortemente a necessidade de uma prolongada formação de professores. Quanto ao ensino propriamente dito, propõe:

Não assustar o aluno com excessiva simbologia, fonte de fortes antipatias e da incompreensão da escrita matemática. Não perder de vista o carácter utilitário da disciplina, principalmente para os que se ficam, e são a maioria, nos cursos de formação profissional (VELHO, 1967, p. 11).

Continua afirmando que não está a ver como pode a Matemática coordenar o seu ensino com a Física enquanto "estiver absorvida pelo estudo dos fundamentos, designadamente pela teoria dos conjuntos" (VELHO, 1967, p. 11-12). Cético, afirma contundentemente:

Para além de ministrarmos uns tantos rudimentos da Álgebra de Boole, ou levarmos um ano inteiro a fazermos sucessivas ampliações da ideia de número até chegarmos aos espaços vectoriais, aos complexos e às matrizes, o que interessa [noutro local chama-lhe "ponto crucial"] é a futura 
transferência de toda essa aprendizagem numa matemática utilitária, capaz de resolver os problemas correntes da oficina do serralheiro ou do eletricista que julgo continuarão ainda por muitos anos afastados na teoria e na prática, dos calculadores electrónicos, da organização interna dos cristais, dos semicondutores, e de tantas outras especializações da física e da tecnologia modernas (VELHO, 1967, p. 12).

Outros docentes apontaram preocupações com a formação de professores. Muitos não tinham opinião sobre a Matemática Moderna, mas esperavam que a sua introdução fosse positiva.

\section{Desenvolvimento da experiência}

As experiências iniciam-se em 1967-68 com um programa para dois anos (correspondentes aos $7^{\circ}$ e $8^{\circ}$ anos de escolaridade) que incluía o estudo de conjuntos, vetores, transformações geométricas e o conceito de grupo. A álgebra e os ângulos no plano eram desvalorizados, a trigonometria, pelo contrário, ganhava importância. As funções passavam a ser estudadas como casos particulares de relações e deixavam de estar associadas ao estudo da reta no plano coordenado, e alguns temas (proporcionalidade inversa e radiciação) desapareciam (HEITOR, 1967b, p. 4).

A experimentação foi sendo desenvolvida até entrarem gradualmente em funcionamento novos programas no princípio dos anos setenta. Nestes anos de experiência vão ser publicados livros de texto da autoria dos membros da comissão para a implementação da reforma e através deles podemos observar como se foram concretizando algumas das propostas iniciais.

Nota-se em primeiro lugar uma extensa incorporação de termos e símbolos associados à teoria de conjuntos. Se, por um lado, este estilo acrescenta novos temas matemáticos, por outro, torna mais abstrata a explicação das matérias. Na figura 3, por exemplo, observamos um dos livros experimentais abordando um tema que não fazia parte dos anteriores programas, a existência de inverso na multiplicação com racionais. 


\section{Existência dum Inverso para a Multiplicação em 0 。}

Suponhamos um elemento qualquer de $\mathrm{Q}_{\mathrm{o}}$, isto é $\neq 0$. Por exemplo, $\underline{3}$. Temos que:

$$
\begin{aligned}
\frac{3}{4} \times \frac{4}{3}= & \frac{3 \times 4}{4 \times 3}= \\
& =\frac{12}{12}= \\
& =1
\end{aligned}
$$

Da mesma forma:

$$
5 \times \frac{1}{5}=1
$$

isto é:

$$
\forall \frac{n}{m} \in \mathbb{Q}_{0}, \ni \frac{m}{n} \in \mathbb{Q}_{0} ; \frac{n}{m} \times \frac{m}{n}=1
$$

Todo o elemento em $Q_{0}$ tem um inverso para a multiplicação.

Figura 3 - O uso da nova linguagem

Fonte: BISCAIA et al., 1971, p. 37.

$\mathrm{Na}$ figura, a nova linguagem introduz termos (números racionais) e símbolos $\left(\forall, \exists, \in,:, Q_{0}\right)$ que são utilizados para produzir afirmações apenas compreensíveis para quem domine a nova linguagem matemática. Embora significante do ponto de vista matemático, quer o tema, quer a forma escolhida, teriam um duvidoso enquadramento nas finalidades do ensino técnico da altura.

Existem temas antigos que são abordados de forma inovadora, por exemplo, a proporcionalidade direta que era um tema nobre dos programas anteriores com ligações à regra de três e ao estudo das funções, é agora abordada com uma linguagem vetorial e associada às transformações geométricas (Figura 4), perdendo muito da sua aplicabilidade. 
Sabe já que a projeção paralela transporta a graduação de uma recta para outra:

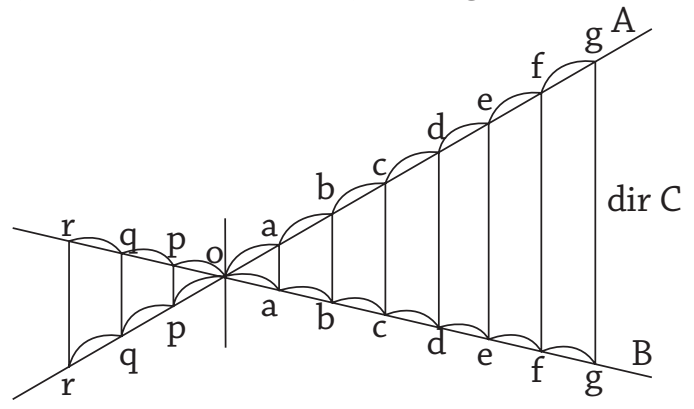

Observa agora, a figura e completa:

Se $\overrightarrow{o b}=2 x \overrightarrow{o a}$, então $\overrightarrow{o b}=\ldots \times \overrightarrow{o a}$

Se $\overrightarrow{o b}=\ldots \times \overrightarrow{o c}$, então $\overrightarrow{o b}=\ldots \times \overrightarrow{o c}$

Se $\overrightarrow{o r}=-\underline{3} \times \overrightarrow{o b}$, então $\overrightarrow{o r}=\ldots \times \overrightarrow{o b}$

2

Figura 4 - A linguagem dos vetores

Fonte: GOMES; PEREIRA, 1972, p. 77.

Os livros experimentais mantêm, no entanto, uma preocupação com as aplicações dos conhecimentos a outras áreas do saber. A Figura 5 mostra como a terminologia própria da matemática moderna é utilizada em um problema envolvendo a comparação entre os raios e a área dos círculos.

Nota-se ainda a preocupação dos autores com o detalhamento dos sucessivos passos da explicação. Neste livro, em particular, o capítulo "Composição de aplicações (revisão)" atravessa diversos temas matemáticos (proporcionalidade, composição e inversão de aplicações, cónicas) e usa a linguagem moderna para abordar situações reais: Tais como a instalação de uma mina, rodas dentadas, áreas e pesos de chapas de ferro, etc. recorrendo simultaneamente a múltiplas representações matemáticas. 


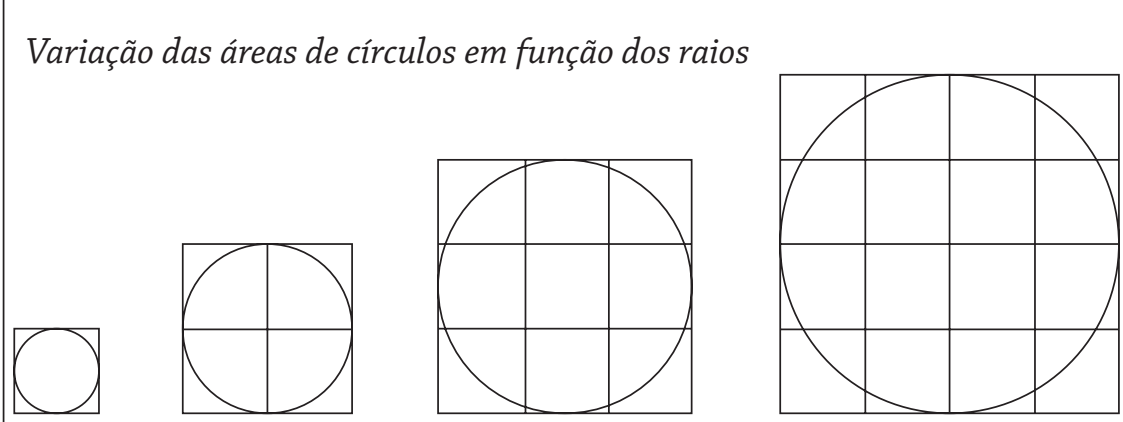

A função que vamos estudar é

O exame da figura faz-nos imediatamente reconhecer que, quando o raio duplica, a área aumenta mais que para o dobro, etc. $\mathrm{O}$ quadro de valores seguinte esclarece melhor esta variação.

\begin{tabular}{|c|c|c|}
\hline Raios & $\begin{array}{c}\text { Quadrados } \\
\text { dos raios }\end{array}$ & \\
\hline 1 & 1 & 3,14 \\
\hline 2 & 4 & 12,56 \\
\hline 3 & 0 & 28,26 \\
\hline$\cdot$ & . & $\cdot$ \\
\hline . & . & . \\
\hline . & . & . \\
\hline$r$ & $r$ & $\pi r$ \\
\hline
\end{tabular}

Os valores da 3. ${ }^{\text {a }}$ coluna obtêm-se, a paritir dos da 2.a , multiplicando estes pela constante 3,14 .

Vemos, pois, que há proporcionalidade directa entre os valores de áreas e os dos quadrados dos raios, ou abreviadamente:

As áreas dos círculos são directamente proporcionais aos quadrados das medidas dos raios

A fórmula que exprime esta proporcionanalidade é $S=\pi r^{2}$ em que $\pi$ é a constante de proporcionalidade

Figura 5 - A linguagem da matemática moderna e aplicações Fonte: BISCAIA et al., 1971, p. 64. 


\section{Conciderações Finais}

A introdução da matemática moderna no ensino técnico vai obrigar a refazer a cultura escolar nesse ramo de ensino. Para além de uma recomposição das normas, dando um caráter mais generalista e mais abstrato à formação, as práticas vão ser afetadas exigindo uma adaptação de métodos e de tecnologia escolar (exemplos, representações, exercícios e terminologia) que vão afetar a cultura destas escolas.

Este episódio não termina bem. Após a revolução de 1974 as escolas técnicas são transformadas em escolas secundárias, se aproximando do modelo liceal, com o consequente desaparecimento dos saberes especializados associados à especificidade do ensino técnico. Será preciso esperar pelos anos 1980 para ver ressurgir este tipo de ensino (RODRIGUES, 2014), mas, agora, noutro tipo de escolas e em moldes muito distintos.

\section{Referências}

ALMEIDA, L. Palavras do Inspector-Superior do E. T. P., Dr. Leopoldino de Almeida, no encerramento dos Cursos de Actualização e Valorização Didáctica do pessoal docente, em 1969. Escolas Técnicas, Boletim de Acção Educativa, n. 41, p. 9-22, 1970.

BISCAIA, A.; et al. Matemática Cursos Industriais Comerciais e Agrícolas. $1^{\text {a }}$ parte $2^{\circ}$ ano. Edição experimental para o $2^{\circ}$ ano 1971/72. Lisboa: Amílcar de Matos Marques, 1971.

GOMES, F.; PEREIRA, V. Matemática Cursos Gerais de índole industrial. $2^{\mathrm{a}}$ parte / $2^{\circ}$ ano. Edição experimental para 1972/73. Lisboa: Amílcar de Matos Marques, 1972.

HEITOR, A. O. S. A aprendizagem da Matemáticas nas escolas técnicas - I. Escolas Técnicas, Boletim de Acção Educativa, n. 16, p. 155-75, 1954a.

HEITOR, A. O. S. A aprendizagem da Matemática nas escolas técnicas - II. Escolas Técnicas, Boletim de Acção Educativa, n. 17, p. 431-42, 1954b. 
HEITOR, A. O. S. A aprendizagem da Matemáticas nas escolas técnicas - III. Escolas Técnicas, Boletim de Acção Educativa, n. 18, p. 51-62, 1955a.

HEITOR, A. O. S. A aprendizagem da Matemáticas nas escolas técnicas - IV. Escolas Técnicas, Boletim de Acção Educativa, n. 19, p. 33-52, 1955b.

HEITOR, A. O. S. Comentário sobre a XI reunião da Comissão Internacional para o Estudo e Aperfeiçoamento do Ensino da Matemática. Escolas Técnicas, Boletim de Acção Educativa, n. 23, p. 269-84, 1958.

HEITOR, A. O. S. Artigo preparatório do $2^{\circ}$ Curso de Aperfeiçoamento dos Professores de Matemática (E.T.P.). Folha Informativa dos Professores do $1^{\circ}$ Grupo (E. T. P.), n. 9, p. 1-5, 1967a.

HEITOR, A. O. S. Comunicação sobre o $2^{\circ}$ Curso de Valorização e Actualização dos Professores de Matemática. Folha Informativa dos Professores do $1^{\circ}$ Grupo (E. T. P.), n. 10, p. 1-2, 1967b.

JULIA, D. A cultura escolar como objeto histórico. Revista Brasileira de História da Educação, Campinas, São Paulo: SBHE, n. 1, jan-jul, p. 9-43, 2001.

MATOS, J. M. Mathematics education in Spain and Portugal. Portugal. In: A. KARP; G. SCHUBRING (Eds.), Handbook on the History of Mathematics Education. Londres: Springer, 2014. p. 291-302.

MATOS, J. M.; NOVAES, B. W. D.; GABRIEL, L. M. Recompondo a cultura da matemática escolar: a intervenção da Folha Informativa dos Professores do $1^{\circ} \mathrm{Grupo}$ (E.T.P.). Em J. A. FERNANDES; M. H. MARTINHO; F. VISEU (Eds.), XX Seminário de Investigação em Educação Matemática. Viana do Castelo: APM, 2009. p. 228-38.

NOVAES, B. W. O Movimento da Matemática Moderna em escolas técnicas industriais do Brasil e de Portugal: impactos na cultura escolar. Tese (Doutorado em Educação); Pontifícia Universidade Católica do Paraná, Curitiba, 2012. 
PEREIRA, V. J. Alguns apontamentos recolhidos durante o colóquio de Professores de Matemática (Outubro de 1967). Folha Informativa dos Professores do $1^{\circ}$ Grupo (E. T. P.), n. 14, p. 3-9. 1967.

PEREIRA, V. J. $3^{\circ}$ dia - $1^{\mathrm{a}}$ sessão. Folha Informativa dos Professores do $1^{\circ}$ Grupo (E. T. P.), n. 18, p. 13-14. 1968.

PORTUGAL. Decreto $\mathrm{n}^{\circ}$ 37.029, Estatuto profissional industrial e comercial. Diário do Governo, 198, 1948, p. 844-911.

PORTUGAL. Portaria n ${ }^{\circ}$ 13.800 Programas do Ensino Profissional e Comercial. Diário do Governo, 8, 1952, p. 17-236.

REDAÇÃO. Matemática Moderna, porquê? Folha Informativa dos Professores do $1^{0}$ Grupo (E. T. P.), n. 3, p. 1-3. 1967.

RODRIGUES, A. S. A matemática no ensino profissional. Os programas e as representações dos professores. 2014. Tese Doutorado em Didática da Matemática Universidade da Beira Interior, Covilhã, 2014.

SAMPAIO, J. S. A deterioração do professorado. Boletim da Direç̧ão de Serviços do Ciclo Preparatório do Ensino Secundário, n. 12, p. 72-80, 1975.

SILVA, E. R. O primeiro ano de Matemática. Escolas Técnicas, Boletim de Acção Educativa, n. 11, p. 207-234, 1952.

SILVA, E. R. O segundo ano de Matemática. Escolas Técnicas, Boletim de Acção Educativa, n. 15, p. 12-48, 1953.

SILVA, E. R. A Matemática no Ciclo, disciplina de trabalho. Escolas Técnicas, Boletim de Acção Educativa, n. 27, p. 131-40, 1960.

SILVA, E. R.; ALMEIDA, J. A. M. Matemática industrial, $2^{\circ}$ volume (2a ed.). Lisboa: Livraria Sá da Costa, sem data, [>1958]. 
SOUSA, I. M. Manuais escolares de matemática para o Ciclo Preparatório do Ensino Técnico. Dissertação de Mestrado em Ensino de Matemática - Universidade Nova de Lisboa, Almada, 2012.

VELHO, A. V. Respostas ao questionário. Folha Informativa dos Professores do $1^{0}$ Grupo (E. T. P.), n. 14, p. 10-13. 1967.

Recebido: 20/11/2015

Received: 11/20/2015

Aprovado: 16/02/2016 Approved: 02/16/2016 